\title{
Exploration on the Reform and Innovation of the Teaching Mode of Double Degrees in Normal Universities
}

\author{
- A Case Study of Lingnan Normal University \\ Shuiqing Xiao, Caihong Ye, Yuan Gao, Songbo Wang* \\ School of Business \\ Lingnan Normal University \\ Zhanjiang, Guangdong, China
}

\begin{abstract}
With the development of the times, the society has an increasing demand for compound and applied talents, thus promoting the in-depth development of double-degree mode. Taking Lingnan Normal University as case study, this work first utilized the online questionnaire survey method to comprehensively analyze problems existing in the double-degree education work organized by undergraduate colleges and universities, and then put forward some effective countermeasures and suggestions. The results offer references for the future work of double-degree teaching and the cultivation of compound talents, and it can be used as a guide for other colleges and universities to solve similar problems in the teaching of double-degree mode.
\end{abstract}

Keywords-Normal university; Double degrees; Teaching reform; Teaching innovation

\section{INTRODUCTION}

At present, the society is changing with each passing day and the process of economic globalization is accelerating, so the single-type talents are unable to meet the needs of rapid social development. Therefore, since the 1980s, colleges and universities in China have carried out secondary and doubledegree teaching models to explore compound talent training methods in the new era [1-3]. As a normal university with the history of centuries, Lingnan Normal University has added some non-normal majors, such as business and engineering, on the basis of normal majors, and achieved remarkable results, but the double-degree teaching started late. In 2016, the business college of Lingnan Normal University piloted the double-degree teaching of "management" in four majors: ecommerce, financial accounting, business administration as well as international economics and trade. It is designed to provide more choices for undergraduates majoring in nonadministration or non-management majors. It can not only solve the problem that students can't change their majors because of the limited quotas, but also train more high-quality and comprehensive professionals for China and the society to adapt to the social development with a solid foundation, a wide range of knowledge and an interdisciplinary structure.

According to feedback from teachers, students and the society: on the one hand, double-degree teaching is indeed

Funded by the teaching reform project of Lingnan Normal University (No LSJG1721). favored by students and recognized by the society. However, due to various reasons, only one class of "financial accounting" is successfully established. On the other hand, from the perspective of its teaching management mode, there are still some problems that need to be solved. Based on this, this work used the online questionnaire survey method to conduct an anonymous survey of students who take the second degree. According to the statistical analysis of the questionnaires, the universal problems of the double-degree teaching mode of Lingnan Normal University can be analyzed. Combined with the development needs of the times, corresponding countermeasures and suggestions can be put forward, so as to improve the quality of educational services in normal colleges and meet the deep needs of social, economic and cultural development.

\section{MAIN PROBLEMS}

Through investigation and analysis, it is found that Lingnan Normal University has the following main problems in the process of starting a double-degree teaching.

\section{A. Publicity is not enough and the admission threshold is too high}

$85 \%$ of the students are very positive about the "double degree" teaching model, which can bring more opportunities for students who have more ability to learn second professional knowledge, and help to improve their overall quality and future employment choices. However, more than $90 \%$ of the students think that the school's publicity is not enough, and there are fewer publicity channels. At present, the propaganda work is limited to the first week of the each semester. Online, the academic affairs office publishes relevant enrollment brochures on the campus information column; Offline, professional teachers conduct advocacy promotion and answer questions for two days next to Xinyong Supermarket, where students flow most intensively. At the same time, the enrollment threshold for double degrees is too high, requiring elective students to achieve an average score of 75 or more during their freshman year. 
B. The teaching time is fixed, and the teaching mode and method are backward.

$52 \%$ of the students believe that the teaching time is not flexible, which are scheduled on Saturdays and Sundays. When students have important activities for their first professional college on weekends, they can no make a balance between the two sides. Sometimes it's difficult to choose, or they will be criticized for being absent, and even lose the qualification. Similarly, since the teaching time is scheduled on the weekend, experienced professors with high professional titles are reluctant to attend classes, and the college has to arrange for young teachers with less experience to attend classes, resulting in poor teaching quality, which can greatly reduce student learning efficiency. The teaching methods and models are mostly based on traditional teaching methods. In today's era when the Internet has been very developed, it does not make good use of modern new media teaching tools, or make innovation in teaching models and methods.

\section{The curriculum arrangement is unscientific and unreasonable, and the course content is backward.}

$45 \%$ of students believe that the course arrangement is reasonable and the number of hours is acceptable. However, $55 \%$ of students believe that the curriculum arrangement is unscientific and unreasonable, which needs to be improved. Teachers' teaching mode is mostly based on cramming, which requires students to passively accept theoretical knowledge, but make students unable to improve and consolidate their skills, leading to poor teaching effect. The main reason is that in the current curriculum arrangement of double major in financial accounting, most of them are theoretical courses, while practical courses account for little. With the rapid development of society, many knowledge structures and contents have changed constantly, but some teachers still use old textbooks. For example, in the financial accounting major, many financial tasks have shifted to software processing and network management in the network era. At this point, the focus of the teaching content must be transferred. However, many teachers still instill the original manual accounting knowledge, and the obstacles are lagging behind.

\section{Lack of teachers}

At present, there are 2 doctors, 3 professors and 1 associate professor in the accounting professional teachers. The rest are masters or lecturers. There are fewer teachers who are proficient in accounting business and have experience in accounting operations. With the changes of society, the government, enterprises and institutions have increasing demand for computerized accounting personnel. Only excellent teachers can train outstanding students, and the strengthening of the financial accounting profession is impending.

\section{Suggestions ON TEACHING MODEL REFORM AND INNOVATION}

Under the correct leadership of the university, it is of great significance to improve the quality of double-degree teaching in normal universities under the premise of formulating scientific and reasonable double-degree management concepts, rules and regulations. In response to the above problems, the following suggestions on the reform and innovation of teaching models are proposed, which provide reference for promoting the healthy and steady development of double degrees in normal universities

\section{A. Broadening channels, increasing publicity, and appropriately lowering the threshold for enrollment}

Due to the late start of the double-degree teaching in the university, the publicity channel is limited to the university website and the teachers' on-site answering, so that the probability of contact with the students is relatively small, resulting in the phenomenon that only one class is open now which is planned to open four professional double-degree teaching classes. Therefore, universities and secondary colleges should broaden the channels of publicity, not only online and offline promotion, but also vertical publicity. Firstly, the university has to attach importance to the development of double-degree teaching from the top of the administrative management. The clerk and counselor who is responsible for the students work of each secondary college is required to make great publicity in the college, so that every student know that the school has a double-degree elective system. The university should encourage students who have the ability to learn to take a second degree to improve their individual competitiveness. Secondly, the university should print the double-degree training program and system in the Handbook of Daily Behavior of College Students, so that freshmen can learn when they enter school, achieving the purpose of promoting.

In view of the fact that the university is in the initial stage of cultivating talents with double degrees, the admission conditions should be implemented with the system of "wide admission but strict graduation". Appropriately lowering the threshold for enrollment enables every interested student to get the opportunity to study, so as to realize the quantitative change first and then the transition to qualitative change. Different from some colleges and universities in China that have already started double-degree teaching, Lingnan Normal University has to set the threshold since it has a long history of running a school and the number of people enrolled in the second degree is large. According to the threshold, only students who meet certain conditions can choose double degrees, which is conducive to selecting high quality students.

Throughout Lingnan Normal University, it turns out that it does not work to blindly copy the practices of other colleges and universities in the first implementation of double-degree teaching period. On the contrary, Lingnan Normal University should appropriately lower the threshold so that all students have the opportunity to enroll, thus solving the problem of insufficient enrollment in certain majors. Since every undergraduate who can formally pass the college entrance examination proves that he has certain independent learning ability. However, after entering the university, students' interest in the major is not high since the admission major is far from their wishes, leading to an universal phenomenon that the average GPA of the freshman is relatively low. However, this does not mean that students can't learn the second major well that they're interested in. At the same time, the double-degree teaching model should not only be for profit, but should be 
people-oriented and cultivate talents [4, 5]. Even if only one student enrolls, the university should stick to the class. Such a one-on-one coaching and training mode of tutors and students is more humanized and flexible, and it is easier to train highquality talents. Didn't Peking University have a precedent of recruiting only one student a year? While referring to the advanced management methods of other colleges and universities in China, Lingnan Normal University should formulate flexible and applicable policies according to the actual situation of itself and develop characteristics and quality. After a certain period of precipitation and students' word of mouth, it will definitely achieve the effect and realize the transition from quantitative change to qualitative change.

\section{B. Teaching methods and teaching models should implement bold reform and innovation}

It should boldly explore ways to adapt to the new era of teaching methods based on traditional teaching methods, such as mixing the flip classroom method, case lecture method, project practice method, interactive learning, situation simulation, sand table simulation and other teaching methods into the classroom, so as to improve students' interest in learning and improve the quality of teaching. In terms of course arrangement, the academic affairs office should make overall arrangements and take into account the students' first and second major courses as far as possible between Monday and Friday. The teaching mode should open up thinking, combine modern science and technology, realize resource sharing, and boldly innovate. It should also make full use of the dividends brought by the network, especially the $5 \mathrm{G}$ era, achieving the combination of classroom and distance education [6,7]. Each class should be recorded and uploaded in time, so that students who are absent due to important things can make up after class, which can make up for the shortcomings of the traditional teaching mode and fully embody the advantages of the peopleoriented flexible double-degree teaching mode. Through the construction of network learning platform, teachers can appropriately use the class group and other channels for realtime communication, so as to solve problems of students. Teachers can arrange and correct homework online, which can enhance students' practical ability. The team of teachers should be composed of experienced professors and promising young teachers to improve the quality of teaching. Only by striving to explore and practice will there be constant innovation, and only by continuous innovation will there be continuous improvement. Exploring the advanced and flexible teaching methods and means of people-oriented, reforming the teaching management mode of compound talents that is conducive to the development of students' individuality in normal universities, and inspiring the initiative and creativity of students are more conducive to cultivating interdisciplinary talents with the characteristics of normal universities.

\section{Developing a scientific and rational curriculum system and course content}

The curriculum system is formulated in accordance with the established talent training program. The scientific and rational personnel training program determines the rationality of the curriculum system and directly affects the quality of personnel training. Therefore, under the basic framework of cultivating composite application talents, the curriculum system based on the double-degree teaching mode should be diversified and practical. It is especially important to combine theory and practice, allocate rationally, and develop the curriculum system scientifically. The content of the course should be kept up to date. On the basis of fully considering the differences between the main and the minor, teachers should choose new teaching materials and prepare new teaching plans. In some subjects, such as E-commerce, the development of mobile e-commerce changes year by year: from PC to wireless, from B2B, B2C and $\mathrm{C} 2 \mathrm{C}$ mode to $\mathrm{O} 2 \mathrm{O}$, from $\mathrm{O} 2 \mathrm{O}$ to micro-business, from microbusiness to live broadcast and from live broadcast to short videos (Tik Tok). The related e-commerce cases (e-commerce company) have also changed rapidly, some of which go from small to big quickly, some go from big to small or are merged or declared bankrupt. If the teaching materials and cases of the previous years are still used in teaching, it is obviously lagging behind. If some courses cannot find the corresponding new textbooks, it is recommended to set up a research group to discuss and research, and make PPT, teaching plans or selfedited teaching materials suitable for the teaching use, which is better than using outdated textbooks.

\section{Building an excellent teaching team}

The construction of excellent teaching team should be carried out in a step-by-step manner. In the past few years, Lingnan Normal University has recruited a large number of highly educated and highly qualified teachers to complement the teachers of various disciplines. Among them, the business college has added 10 doctors and several professors, and quickly expanded the original teaching team to enhance the teaching resource. In addition to recruiting talents from outside, it is also necessary to give existing young teachers the opportunity to go out for training and self-improvement. The academic backbone should take the lead in doing solid work, actively participate in domestic and international academic conferences, and actively carry out scientific research. Although this is a slow improvement of the situation of teachers, but from their own and long-term development, it is an economic and effective way to stabilize and improve the quality of themselves. The development of the times requires high-quality teachers with knowledge, ability and practical experience, as well as teachers with innovative ability, creative teaching ability and organizational scientific research ability. Building an excellent teaching team is a powerful guarantee for realizing a high-quality talent training model of double degrees.

\section{SUMMARY}

Double-degree teaching is an important measure for colleges and universities to deepen teaching reform cultivate compound talents that meet the needs of the times, and realize the great rejuvenation of the nation. Based on the above research, it is found that Lingnan Normal University has problems of insufficient propaganda, high enrollment thresholds, backward teaching methods, unreasonable curriculum design, mismatched curriculum development and lack of teachers. In response to these major problems, this work gave corresponding countermeasures and suggestions for the reform and innovation of the double-degree teaching model, 
which is of great significance to promote the cultivation of compound talents, develop education and improve the employment competitiveness of students. After steady development, double-degree teaching can also consider the joint school-running model with colleges and universities at home and abroad. In the process of running a school, it is necessary to be brave in continuous exploration and practice, dare to break through and innovate, make progress, and develop characteristics, so that it can find out the roads and methods suitable for its own development, and cultivate more comprehensive and high-quality compound talents.

\section{REFERENCES}

[1] Xu Lei. Research on the Problems and Countermeasures in the Training Mode of the Double-degree and Minor Business Talents - A Case Study of Sichuan International Studies University[J]. Estate and Science Tribune vol. 18 (5) 2019, pp. 143 - 144.
[2] Zhang Hui. Thoughts on the Implementation of Minor and Doubledegree Education in Colleges and Universities[J]. Journal of Weifang University. vol. 18 (1) 2018, pp. 110 - 112(In Chinese).

[3] P. Song, Y. Z. Yang, L. L. Diao. The Main Problems and Countermeasures of Undergraduate Double Degree Education in South China Agricultural University Economics and Management Professional. Higher Education Forum, 31 (5) 2018, pp. 14 - 15(In Chinese).

[4] Y. J. Fan. The Theoretical Framework for Talent Development of Dual Degree of Accounting Discipline, Commercial Economy, vol 5, pp. 121 $-123$

[5] S. Y. Lam, Joseph C. H. So, K. W. Ng. Hong Kong Secondary Education Reform and Its Impact on Social and Cultural Awareness - A comparative Case Study of Associate Degree Freshmen in Hong Kong[C]. 2014 International Conference of Teaching, Assessment and Learning (TALE), pp. 313 - 318.

[6] X. H. Shi. Under the New Education Idea of Higher Vocational Colleges to Explore the Teaching Reform. 2015 8th International Conference on Intelligent Computation Technology and Automation, pp. 1071 - 1074.

[7] L. X. Ma, J. C. Hu, X. J. Liu et al. Teaching Reform and Practice of the Basic Computer Course Based on Flipped Classroom. The 12th International Conference on Computer Science \& Education (ICCSE 2017) August 22-25, 2017. University of Houston, USA, pp. 713 - 716 